\title{
Cerebrovascular disease in dementia: the importance of atrial fibrillation
}

\author{
P.J. Ratcliffe, and G.K. Wilcock
}

Nuffield Department of Clinical Medicine, John Radcliffe Hospital and Department of Geriatric Medicine, Radcliffe Infirmary, Oxford, UK.

\begin{abstract}
Summary: The relationship between cardiovascular disease and cerebral infarction was analysed in a prospectively assessed post mortem series of $\mathbf{4 8}$ demented patients. Hypertension was rare in this group of patients whose mean age was $82.7 \mathrm{y}$. Atrial fibrillation was the most important underlying cardiac abnormality. It is suggested that atrial fibrillation is more important than hypertension in the aetiology of cerebral infarction in the very aged and that this may be relevant to the pathogenesis of cerebrovascular dementia.
\end{abstract}

\section{Introduction}

Cerebrovascular disease is considered to play a role in the pathogenesis of a significant minority of cases of dementia, where it may be the sole pathology or associated with senile dementia of the Alzheimer type (SDAT) (Wells, 1978; Tomlinson et al., 1970). The exact incidence of these pathologies varies in different series, and is likely to be a reflection of the population studied. Prevention, treatment and clinical research will ultimately depend on clinical differentiation and other signs of arteriosclerosis, step-wise progression, focal neurological symptoms and signs are all held to be commoner in cerebrovascular dementia than senile dementia. In particular it has frequently been asserted that severe hypertension is strongly associated with cerebrovascular dementia (Arie, 1973; Hachinski et al., 1974; Freemon, 1976; Marsden \& Harrison, 1972; Heyman, 1978; St. Clair \& Whalley, 1983). We have studied a post-mortem series of patients, who were admitted to a geriatric unit because of dementia, in order to determine the relationship between cerebral infarction and cardiovascular disease in that population.

\section{Patients and methods}

The study group consists of all demented patients admitted under one geriatric medical firm between

P.J. Ratcliffe, M.A., M.R.C.P.; G.K. Wilcock, D.M., M.R.C.P.

Correspondence: P.J. Ratcliffe, Nuffield Department of Clinical Medicine, John Radcliffe Hospital, Oxford, UK.

Aocepted: 6 September 1984
January 1980 and March 1982, who had post-mortem examination. The diagnosis of dementia was, in all cases, made prospectively on the basis of assessments using Hodkinson's test (Hodkinson, 1972) and a modified Kew test (Hare, 1978) carried out on at least two occasions and analysed independently by two observers. Only patients where the diagnosis was agreed are included. To avoid the possibility of underestimating hypertension by spuriously low readings during ill health, the blood pressure was taken as the highest value recorded during a period of stable physical health. Full post-mortem examination was carried out on all cases except that one cerebral hemisphere was used for neurochemical studies reported elsewhere (Wilcock et al., 1982), and not examined for cerebral infarction. The left hemisphere was examined for cerebral infarction. Macroscopic appearances of infarction were confirmed histologically in all cases. SDAT was diagnosed on the basis of quantification of neurofibrillary plaques and tangles (Wilcock and Esiri, 1982) which correlated with reduction in choline acetyltransferase activity (Wilcock et al., 1982). Parkinson's disease was diagnosed where there was loss of pigmented cells in substantia nigra associated with pigment incontinence and lewy bodies. Pick's disease was diagnosed by finding the characteristic macroscopic features together with cortical neuronal loss and typical Pick's cells in the cortex. Atheroma at the base of the brain was graded $0-3,0=$ no atheroma, $1=$ minimal atheroma, $2=$ moderate atheroma and $3=$ severe atheroma. This assessment and the extracranial post mortem examination was made before examination of the intracerebral pathology.

(C) The Fellowship of Postgraduate Medicine, 1985 


\section{Results}

Forty eight demented patients had necropsies within the study period. The average age was $82.7 \mathrm{y}$. There were 23 men and 25 women.

\section{Cerebral pathology}

Cerebral pathology in all patients is shown in Table $\mathrm{I}$. Seventeen $(35 \%)$ patients had areas of cerebral infarction. In $7(14 \%)$ this was the only pathology and in 10 $(21 \%)$ it was combined with either SDAT or Parkinson's disease. Twenty-four (50\%) patients had SDAT as the sole pathology so that in total these changes were present in $32(67 \%)$ patients.

The average age of the cerebral infarction group, $81.4 \mathrm{y} \pm 5.7$ (s.d.) was similar to those without cerebral infarction, $82.5 y \pm 6.7$ (s.d.). More men (11) than women (6) had cerebral infarction although the difference did not reach statistical significance. Although histories were sometimes incomplete, a history of at least one sudden focal neurological episode was obtained in 9 of the cerebral infarction group but in none of the others.

\section{Circle of Willis atheroma}

In the group with cerebral infarction Circle of Willis atheroma was graded 0 or 1 (none or minimal) in 5 patients and 2 or 3 (moderate or severe) in 11 patients. In one patient no report was available. In the group without cerebral infarction 20 patients had Circle of Willis atheroma graded 0 or 1 and 11 had grades 2 or 3 . This difference just fails to reach statistical significance $(P=0.06$, Chi-square test using Yates' correction).

\section{Hypertension}

In only 4 patients in the whole group had hypertension been diagnosed and treated, one with cerebral infarc-
Table I Cerebral pathology in 48 demented patients

\begin{tabular}{llc}
\hline & & Patients \\
\hline SDAT $\dagger$ & alone & 24 \\
$(n=32)$ & + cerebral infarction & 8 \\
Cerebral infarction & alone & 7 \\
$(n=17)$ & + SDAT & 8 \\
& + Parkinson's disease & 2 \\
Pick's disease & & 1 \\
Parkinson's disease & alone & 4 \\
$(n=6)$ & + cerebral infarction & 2 \\
No pathology & & 2
\end{tabular}

† Senile dementia of Alzheimer type. The figures indicate the number of patients showing the pathology.

tion, and three in the group without. The mean blood pressure was $153 \mathrm{~mm} \mathrm{Hg} \pm 28$ (s.d.) for the group with cerebral infarction and $145 \mathrm{~mm} \mathrm{Hg} \pm 20$ (s.d.) in those without cerebral infarction. No patient had a diastolic blood pressure greater than $110 \mathrm{~mm} \mathrm{Hg}$. Mild hypertension (diastolic blood pressure $100-110 \mathrm{~mm} \mathrm{Hg}$ ) occurred in $5(29 \%)$ of those with cerebral infarction and $5(16 \%)$ of those without. This difference failed to reach statistical significance (Chi-square test with Yate's correction) (Table II).

\section{Myocardial disease}

Five patients had full thickness myocardial infarction and 5 more had minor partial thickness myocardial scars. There was no correlation with cerebral infarction (Table II).

\section{Valvular heart disease}

Two patients had rheumatic mitral valve disease, one had significant degenerative aortic valve disease. A further 5 had minor degenerative valvular lesions such

Table II Cardiac disease in $\mathbf{4 8}$ demented patients

\begin{tabular}{|c|c|c|}
\hline & $\begin{array}{c}\text { Cerebral } \\
\text { infarction }\end{array}$ & $\begin{array}{l}\text { No } \\
\text { infarction }\end{array}$ \\
\hline $\begin{array}{l}\text { Hypertension diastolic }>110 \mathrm{~mm} / \mathrm{Hg} \\
\text { Atrial fibrillation } \\
\text { Myocardial scars } \\
\text { Aortic valve disease } \\
\text { Mitral valve disease } \\
\text { Heart weight (mean } \pm \text { s.d.) }{ }^{+}\end{array}$ & $\begin{array}{ll}0 & \\
5 & (29 \%) \\
8 * & (47 \%) \\
3 & (18 \%) \\
2 & (12 \%) \\
1 & (6 \%) \\
344 \pm 77 g\end{array}$ & $\begin{array}{ll}0 & \\
5 & (16 \%) \\
2 * & (6 \%) \\
7 & (23 \%) \\
3 & (10 \%) \\
2 & (6 \%) \\
324 \pm 54 g\end{array}$ \\
\hline
\end{tabular}

+ Patients without myocardial or valvular heart disease.

$* P<0.01$. 
as calcification of the cusps. There was no correlation between cerebral infarction and valvular disease (Table II).

\section{Heart weight}

The mean cardiac weight for those patients who had no evidence of myocardial scarring or valvular disease was $344 \mathrm{~g} \pm 77$ (s.d.) for those with cerebral infarction and $324 \mathrm{~g} \pm 54$ (s.d.) for the group without cerebral infarction. Nine of these patients without other cardiac disease had heart weights above an arbitrary limit of $400 \mathrm{~g}$ for men, and $350 \mathrm{~g}$ for women. Four of these had cerebral infarction and 5 did not (Table II).

\section{Atrial fibrillation}

Atrial fibrillation was present in $8(47 \%)$ of those with cerebral infarction in contrast to $2(6 \%)$ of those without. This difference is statistically significant using the Chi-square test with Yate's correction, $(P=<0.01)$ (Table II). Only one patient with atrial fibrillation had a history of hypertension, one had full thickness myocardial infarction and another had a small myocardial scar. None had rheumatic valvular heart disease.

Left atrial thrombus was found in one patient who was in sinus rhythm without evidence of other cardiac disease. There was no cerebral infarction but the patient died from an ischaemic left leg.

\section{Discussion}

We have surveyed the cardiovascular risk factors associated with cerebral infarction in a group of demented patients referred to a geriatric firm. The diagnosis of dementia was made prospectively and patients who died underwent careful neuropathological post-mortem examination. Since the group was collected primarily for the study of SDAT, only one hemisphere was examined for infarction and the volume of infarction was not quantified. Some small cerebral infarcts confined to the other hemisphere may have been missed and these patients wrongly assigned to the no infarct group. This will tend to decrease the power of the study to detect relatively weak risk factors for cerebral infarction. Nevertheless, we have a group of patients with carefully acquired pre- and post-mortem data, permitting an assessment of the relative importance of cardiovascular risk factors. Our study cannot determine the precise contribution of cerebral infarction to dementia but the $14 \%$ incidence of cerebral infarction as the sole pathology and a further $21 \%$ in association with other pathology is similar to that reported by Tomlinson et al. (1970) who felt that cerebral infarction contributed to dementia.
A correlation between cerebral infarction and atheroma of the Circle of Willis had been noted previously in demented patients (Corsellis, 1975). In our study this correlation was weak and just failed to reach conventional statistical significance.

None of our patients had severe hypertension. The low prevalence of hypertension was not due to the hypotensive effect of intercurrent illness as blood pressure used was the highest recorded and all patients had been observed in good physical health for at least one month as a criterion for the valid diagnosis of dementia. Mild hypertension was commoner in the infarction group but the difference did not reach statistical significance. It is possible that a past history of hypertension was underreported. The relationship of heart weight to past or present hypertension is difficult to determine as both cardiac infarction and valvular disease also lead to hypertrophy. However, the incidence of hypertrophy in hearts without myocardial scarring or valvular disease was no different in the group with cerebral infarction. The slightly higher average heart weight in the group with cerebral infarction is probably due to the association of cerebral infarction with male sex in our patients. Several studies which describe a strong association between hypertension and cerebrovascular dementia (Hachinski et al, 1974; Marsden \& Harrison, 1972; St. Clair \& Whalley, 1983) deal with younger patients. Our data in a much older population are in conflict with the view that cerebrovascular dementia is usually associated with severe hypertension and important because it is in this age group that dementia is most common.

Myocardial infarction and valvular disease were not found to be more common in patients with cerebral infarction. In a large survey, Hontela \& Schwartz (1979) found an association between cardiac infarction and cerebral infarction in a psychogeriatric population. Although it is likely that most of these patients were demented no details of the diagnosis are given. In our population, full thickness myocardial infarction was not common and it is quite possible that a study of this nature would fail to pick up a relatively weak association with cerebral infarction.

Atrial fibrillation was strongly associated with cerebral infarction. However, although recognised as a risk factor for stroke, atrial fibrillation has received little attention as an aetiological factor in cerebrovascular dementia and is not mentioned as a risk factor in studies using an ischaemia index to differentiate cerebrovascular from senile dementia (Hachinski $e t$ al, 1975; Loeb and Gandolfo, 1983). In recent studies of acute stroke patients (Lowe et al., 1983; Lovett et al, 1981; Greenland et al, 1981) the prevalence of atrial fibrillation is reported between 9 and $25 \%$ which is much higher than that in population studies such as that by Campbell et al. (1974) where atrial fibrillation 
was found in $2 \%$ of those aged $65-74$ and $5 \%$ of those aged 75 or more. In our patients, the incidence was even higher, perhaps a reflection of the great age of our study group, and the fact that most had multiple areas of cerebral infarction. Most (70\%) of our patients with atrial fibrillation had no other cardiac pathology and were normotensive. None had intracardiac thrombus. Although cerebral infarction in atrial fibrillation is usually held to be due to atrial thrombosis and embolism, cardiac thrombus is rarely detectable even at the time of the event (Lovett et al., 1981; Greenland et al., 1981). Thrombus may, however, be small and transient or atrial fibrillation simply a marker for some other process predisposing to cerebral infarction

\section{References}

ARIE, T. (1973). Dementia in the elderly: diagnosis and assessment. British Medical Journal, 4, 540.

CAMPBELL, A., CAIRD, F.I. \& JACKSON, T.F.M. (1974). Prevalence of abnormalities of electrocardiogram in old people. British Heart Journal, 36, 1005.

CORSELLIS, J.A.N. (1975). The pathology of dementia. British Journal of Psychiatry, Special no. 9, 110.

FREEMON, F.R. (1976). Evaluation of patients with progressive intellectual deterioration. Archives of Neurology, 33, 658.

GREENLAND, P., KNOPMAN, D.S., MIKELL, F.L., ASINGER, R.W., ANDERSON, D.C., \& GOOD, D.C. (1981) Echocardiography in diagnostic assessment of stroke. Annals of Internal Medicine, 95, 51.

HACHINSKI, V.C., LASSEN, N.A. \& MARSHALL, J. (1974). Multi-infarct dementia: a cause of mental deterioration in the elderly. Lancet, ii, 207.

HACHINSKI, V.C., ILIFF, L.D., ZILHKA, E., DU BOULAY, G.H., MCALLISTER, V.L., MARSHALL, J., ROSS RUSSELL, R.W. \& SYMON, L. (1975). Cerebral blood flow in dementia. Archives of Neurology, 32, 632.

HARE, M. (1978). Clinical check-list for diagnosis of dementia. British Medical Journal, 2, 266.

HEYMAN, A. (1978). Differentiation of Alzheimer's disease from multi-infarct dementia. In Alzheimer's Disease: Senile Dementia and Related Disorders Katzman, R., Terry, R.D., Bick, K.L., (eds), Raven Press: New York.

HODKINSON, H.M. (1972). Evaluation of a mental test score for assessment of mental impairment in the elderly. Age and Ageing 1, 233.

HONTELA, S. \& SCHWARTZ, G. (1979). Myocardial infarc- such as carotid disease. Despite the widespread use of anticoagulation in the prevention of embolism where atrial fibrillation is associated with rheumatic heart disease there are no clear data on the effect of anticoagulation in non-rheumatic atrial fibrillation. Our results show a strong association between atrial fibrillation and cerebral infarction in demented patients and we suggest that the role of atrial fibrillation has been underestimated in the pathogenesis of cerebrovascular dementia and that of hypertension overestimated. Further study of the relationship of atrial fibrillation to cerebral infarction and its prevention is urgently needed.

tion in the differential diagnosis of dementias in the elderly. Journal of the American Geriatrics Society, 27 (3), 104.

LOEB, C. \& GANDOLFO, C. (1983). Diagnostic evaluation of degenerative and vascular dementia. Stroke, 14 (3), 399.

LOVETT, J.L., SANDOK, B.A., GIULIANI, E.R. \& NASSER, F.N. (1981). Two-dimensional echocardiography in patients with focal cerebral ischaemia. Annals of Internal Medicine, 95, 1.

LOWE, G.D.O., JAAP, A.J. \& FORBES, C.D. (1983). Relation of atrial fibrillation and high haematocrit to mortality in acute stroke. Lancet, i, 784.

MARSDEN, C.D. \& HARRISON, M.J.G. (1972). Outcome 0 investigation of patients with presenile dementia. Britis/ Medical Journal, 2, 249.

ST. CLAIR, D. \& WHALLEY, L.J. (1983). Hypertension, multiinfarct, dementia and Alzheimer's disease. British Journal of Psychiatry, 143, 274.

TOMLINSON, B.E., BLESSED, G. \& ROTH, M. (1970). Observations on the brains of demented old people. Journal of the Neurological Sciences, 11, 205.

WELLS, C.E. (1978). Role of stroke in dementia. Stroke. 9 (1), 1.

WILCOCK, G.K. \& ESIRI, M.M. (1982). Plaques, tangles and dementia: a quantitative study. Journal of the Neurological Sciences, 56, 343.

WILCOCK, G.K., ESIRI, M.M., BOWEN, D.M. \& SMITH, C.C.T. (1982). Alzheimer's disease: Correlation of cortical choline acetyltransferase activity with the severity of dementia and histological abnormalities. Journal of the Neurological Sciences, 57, 407. 